\title{
Descripción Histológica de la Cámara Incubatriz de Moina hutchinsoni (Brem, 1937)
}

\author{
Histological Description of the Brood-chamber of Moina hutchinsoni (Brem, 1937)
}

\author{
Elizabeth Góngora-Landeros; Esther A. Uría-Galicia; Felipe Fernando Martínez-Jerónimo \& Edgar Oliver López-Villegas
}

GÓNGORA-LANDEROS, E.; URÍA-GALICIA, E. A.; MARTÍNEZ-JERÓNIMO, F. F. \& LÓPEZ-VILLEGAS, E. O. Descripción

histológica de la cámara incubatriz de Moina hutchinsoni (Brem, 1937). Int. J. Morphol., 28(4):1025-1030, 2010.

RESUMEN: Los cladóceros son partenogenéticos por lo que la mayor parte del año, las poblaciones consisten enteramente de hembras que se reproducen asexualmente, en ellas el ovario se comunica por medio de un oviducto, con la cámara incubatriz, la cual se localiza en el margen interno posterior del caparazón, cerca del corazón y antes del intestino. Los huevos provenientes de los oviductos se depositan en la cámara y se incuban hasta terminar el desarrollo embrionario. Se considera que Moina presenta un desarrollo postembrionario directo, porque los organismos juveniles o neonatos, salen completamente formados e independientes durante la muda. En la reproducción asexual la cámara contiene a las diferentes etapas del desarrollo embrionario llamadas; ovocito, huevo y embrión. En la etapa sexual o gamogenética la cámara contiene un efipio con dos huevos. La cámara incubatriz histológicamente esta conformada por un epitelio plano simple, que descansa sobre una membrana basal evidente, la cual se continúa con el tejido conjuntivo laxo, después del cual se encuentra el caparazón. En el interior de la cámara se identificaron los ovocitos, huevos y algunas etapas del desarrollo embrionario, en cortes semifinos y finos por microscopia óptica y de transmisión, respectivamente.

PALABRAS CLAVE: Moina hutchinsoni; Ultraestructura; Cámara incubatriz; Efipio; Desarrollo embrionario.

\section{INTRODUCCIÓN}

Las 11 familias de Cladocera contienen cerca de 800 especies de crustáceos sobre todo planctónicos y bénticos de agua dulce. Los cladóceros son pequeños (0.2-6 milímetros). La mayoría coexisten con los rotíferos y los copépodos y constituyen la mayor parte del zooplancton de agua dulce. Los dos ojos compuestos están fundidos. Un ojo naupliar está presente. El cuerpo se comprime lateralmente. Nadan mediante los movimientos del $2^{\circ}$ par de antenas, las cuales están muy desarrolladas como órganos locomotores, pero las primeras se diferencian en que son rudimentarias en las hembras y más grandes en los machos (Kotov et al., 2005). Se alimentan por medio del filtrado del agua usando la cerda de los apéndices torácicos, que están modificados para filtrar de forma pasiva, tanto, algas como acumulaciones de bacterias, detritos orgánicos y partículas de arcilla con materia orgánica adsorbida, que midan entre 10 y $35 \mathrm{~mm}$ (Martínez, 1976). Algunos son carnívoros y depredadores de otros cladóceros (Rottmann et al., 2003).

Los crustáceos se atraen por medio de feromonas para su reproducción después de la muda, el ciclo repro- ductivo de Moina tiene una fase sexual (gamogénesis) y una asexual (partenogénesis) (Montellano-Rosales \& Mendoza-Vallejo, 1994). Banta \& Brown (1929) encontraron para Moina macrocopa tres fases: la captura, el posicionamiento y la cópula. Forro (1997) al experimentar con la reproducción de Moina brachiata descubre que los machos seleccionan a las hembras sin fertilizar con lo que concluye que no solo las señales visuales y táctiles facilitan la elección de las hembras por los machos sino también las señales químicas. En verano, cuando las condiciones son óptimas las hembras se reproducen por partenogénesis, que consiste en el desarrollo de un organismo a partir de un óvulo no fecundado, en este caso se produce progenie femenina numerosa y resulta mucho más eficiente que la reproducción sexual (Curtis \& Barnes, 2001). El sistema reproductor, de las hembras de los cladóceros está compuesto por los ovarios, que son tubos o sacos largos derivados de los espacios celómicos y se localizan a lo largo del tórax, al lado del intestino. El ovario se abre, vía un oviducto, en la cámara incubatriz que esta situada posteriormente debajo 
del caparazón dorsal. Los huevos se incuban en la cámara, hasta terminar el desarrollo embrionario, y continúan con un desarrollo postembrionario directo o indirecto dependiendo del Género (Fox, 2006).

Brusca \& Brusca (2005) mencionan que los cladóceros, presentan durante la embriogénesis las siguientes etapas: huevo centrolecito, segmentación en espiral holoblástica, blastulación con celoblástula, gastrulación por ingresión y organogénesis. Scharm (1986) indica que Moina, continua con un desarrollo postembrionario directo, ya que los organismos salen de la cámara incubatriz completamente formados e independientes durante la muda. Fox menciona que en Daphnia, se lleva a acabo un desarrollo postembrionario indirecto ya que pasa por un estado larval.

Daphnia es uno de los géneros más representativos de los cladóceros, es considerado en la actualidad como un organismo modelo, ya que ha sido utilizado en una gran cantidad de estudios en investigaciones biológicas (De Bernardi \& Peters, 1987). Sin embargo, Daphnia frecuentemente forma parte del plancton de la zona limnética en las regiones templadas, siendo rara su presencia en los cuerpos de agua tropicales (Fernando et al., 1987), lo que reduce la posibilidad de estudiar a este organismo en otro tipo de condiciones. Moina hutchinsoni tiene un alto rango de tolerancia salina, esta especie se encontró inicialmente en los Lagos de Winnemucca en Nevada; y se distribuye en el Great Basin en Nevada y el Grand Coulee en Washington en los Estados Unidos (Goulden, 1968), existe además el reporte de Martínez-Jerónimo et al. (2004) quienes la encontraron en el lago de Texcoco cercano a la ciudad de México el cual presentaba un alto nivel de salinidad y de contaminación.

Moina hutchinsoni se distingue de otras especies por tener una espina distal del postabdomen, sencilla. El diente distal en el postabdomen es unidentado, raramente bidentado o está ausente. Tiene una cabeza redondeada, con una depresión supraocular leve. El ojo tiene un tamaño moderado con respecto a su cuerpo. Las antenas son cortas y densas. Las segundas antenas están bien desarrolladas. Su caparazón está formado por dos valvas. En el borde ventral de este se alinean cerca de cuarenta setas. En el margen interno posterior se encuentra la cámara incubatriz cerca del corazón y antes del intestino. En la cámara incubatriz durante la reproducción asexual se desarrollan el ovocito, huevo y embrión, y en la sexual se forma un efipio conteniendo dos huevos (Martínez-Jerónimo et al., 2004). Esta especie se logro cultivar en el laboratorio, alimentándola con microalgas Ankistrodesmus falcatus (de agua dulce) y Chlorella sp. ( de agua salada); la temperatura del cultivo se mantuvo entre $15^{\circ}$ y $20^{\circ} \mathrm{C}$, y la salinidad en un rango de 5-25 g L-1. Los especímenes cultivados de esta manera fueron significativamente mayores que los de campo (Martínez-Jerónimo et al., 2004). Para la clasificación de Moina hutchinsoni se considera la de Elías et al. (2008) quienes recopilan información de Goulden y MartínezJerónimo et al., (2004).

Los estudios que se han realizado con este organismo son principalmente de tipo taxonómico (Goulden; Elías et al., 2008), anatómicos (Martínez-Jerónimo et al., 2004; Fox), toxicológicos (Mac-Quhae et al., 2007; MartínezJerónimo et al., 2008) y ecológicos (Rodríguez-Estrada, 2003; Villalobos \& González, 2006), no encontrando hasta la fecha reportes de tipo histológico para la cámara incubatriz. En este trabajo se describen e identifican por medio de microscopía óptica y de transmisión, las estructuras histológicas que forman la cámara incubatriz y las que se desarrollan en su interior: ovocitos, huevos y embriones, para para comprender su ciclo biológico en condiciones de laboratorio, su posible reintroducción en las áreas naturales donde se encontró inicialmente por ser una especie athalosohalina y además, su empleo como un organismo de prueba.

\section{MATERIAL Y MÉTODO}

Los ejemplares para este estudio fueron proporcionados el Dr. Fernando Martínez Jerónimo de material obtenido inicialmente en el Lago de Texcoco en una zona contaminada por la fábrica de Sosa Texcoco y que se mantienen en cultivo en el Laboratorio de Hidrobiología Experimental de la Escuela Nacional de Ciencias Biológicas, Instituto Politécnico Nacional. Se fijaron 27 ejemplares de Moina hutchinsoni de la siguiente manera: 9 con formaldehido al $10 \%$ en regulador de fosfatos para ser fotografiados con el microscopio estereoscópico de campo oscuro con la cámara incubatriz vacía y embriones, con aumentos de 50x. 8 ejemplares fueron fijados con glutaraldehido al $2.5 \%$ por 48 horas para obtener cortes semifinos y finos, éstos se procesaron para incluirlos en resina sintética, de la siguiente forma: tres cambios de 5 minutos cada uno con amortiguador de fosfatos salino (PBS) para eliminar el fijador, postfijación con tetróxido de osmio (OsO4) al 2\% durante 1 hora, después tres cambios de 5 minutos cada uno con amortiguador de fosfatos salino (PBS), deshidratación con alcoholes desde $40 \%$ hasta alcohol al 100\%, una transición con óxido de propileno con dos cambios de 20 minutos cada uno para obtener bloques para luego colocarse en resina $1: 1$ por 1 hora, $1: 2$ por 1 hora, 1:3 por 24 horas y resina $100 \%$ por 24 horas. Se realizaron cortes 

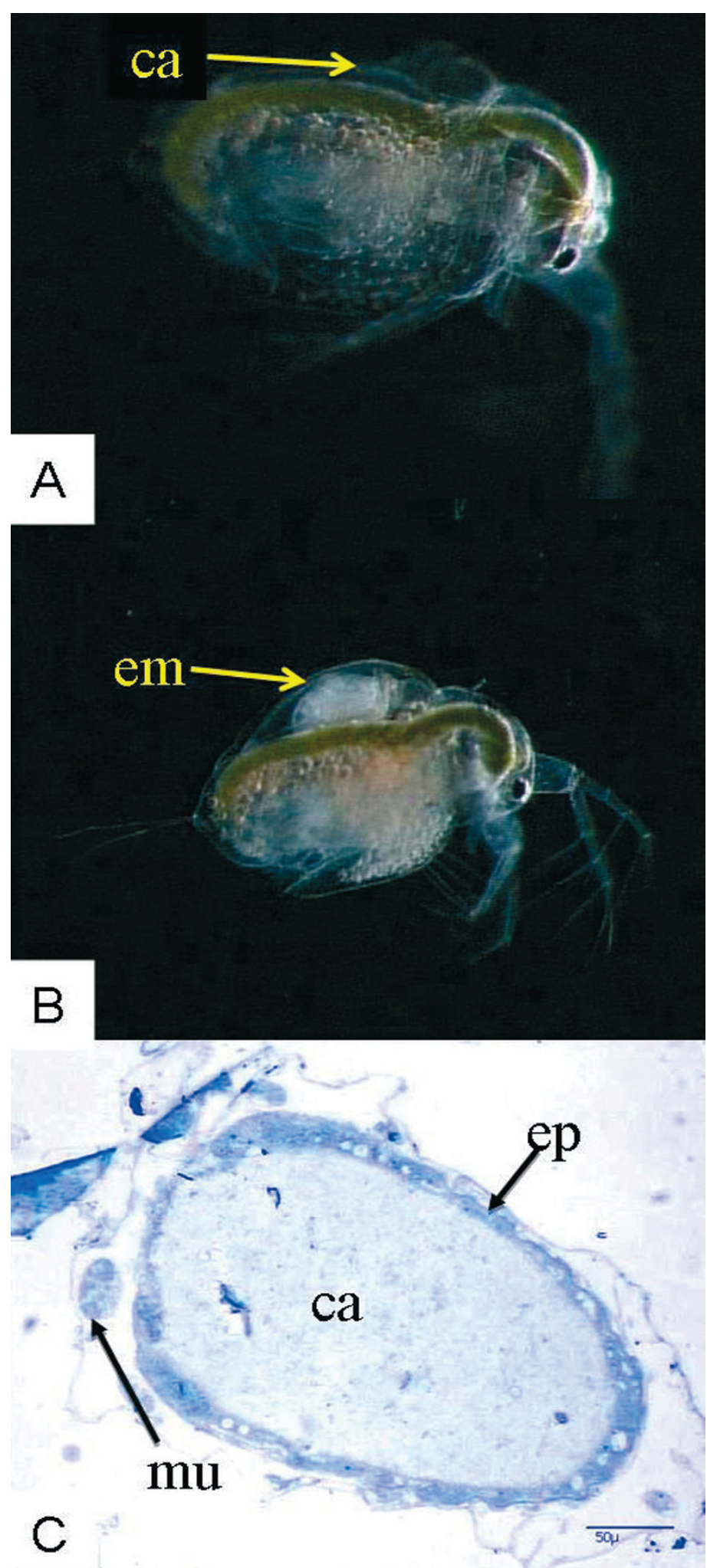

Fig. 1. Moina hutchinsoni. A. Se observa al ejemplar con la cámara incubatriz (ca) vacía. B. Ejemplar con embriones (em) en la cámara incubatriz. C. Cámara incubatriz (ca), músculo (mu), epitélio plano simple de la cámara incubatriz (ep). semifinos con ultramicrótomo Leika, Ultracut UCT de 150 a 300 nanómetros, se contrastaron con azul de toluidina ${ }^{\circledR}$ E.M.S., se montaron con entellan ${ }^{\circledR}$ Merck KGaA y se fotografiaron en microscopio de campo claro marca ZEISS Modelo Axiophot 1 a aumentos de 20x, 40x y 100x.

Posteriormente, se obtuvieron los cortes finos de 65 nanómetros, se contrastaron con acetato de uranilo al 4\% y citrato de plomo de Reynolds, y se colocaron sobre rejillas de cobre de 200 mallas. El material se fotografió en el microscopio de transmisión marca Jeol, Modelo JEM 1010 con un voltaje de 60000voltios, con aumentos de $2 \mu \mathrm{m}$ y $500 \mathrm{~nm}$. En ambos casos se identificaron y describieron las estructuras histológicas del epitelio de la cámara incubatriz, ovocito, huevo y embriones.

\section{RESULTADOS}

En las fotografías de los organismos fijados en formol al 10\% en regulador de fosfatos se evidencia la cámara incubatriz vacía y con embriones (Fig. 1, A y B). En los cortes semifinos se observa que la cámara incubatriz está formada por un epitelio plano simple que descansa sobre una membrana basal evidente a continuación de la cual hay tejido conjuntivo laxo que forma una cápsula fina que la protege (Fig. 1, C) a continuación se encuentra el caparazón. En la luz de la cámara se observa un material granuloso fino y un ovocito con citoplasma, núcleo y nucléolo evidente (Fig. 2, E). En el interior de la cámara incubatriz de otro ejemplar se encuentra un huevo formado por células con citoplasma y núcleo (Fig. 3, G) y en otro, en el interior de la cámara se aprecia un embrión con apéndices toráxicos y cabeza (Fig. 4, I).

En los cortes finos se observan estructuras o figuras mielinicas en el epitelio plano simple de la cámara incubatriz, membrana basal (Fig. 2. D.) $\mathrm{y}$ en el interior de la cámara, se observa un ovocito con citoplasma, núcleo, mitocondrias y aparato de golgi (Fig. 2, F). En otros ejemplares el huevo está en división celular, mostrando células con estructuras mielinicas y material granular electródenso y menos electródenso (Fig. 3, H). Las células en el embrión contienen mitocondrias, material granular electródenso y menos electródenso que puede corresponder a material de reserva o inclusiones de residuos (Fig. 4, J). 

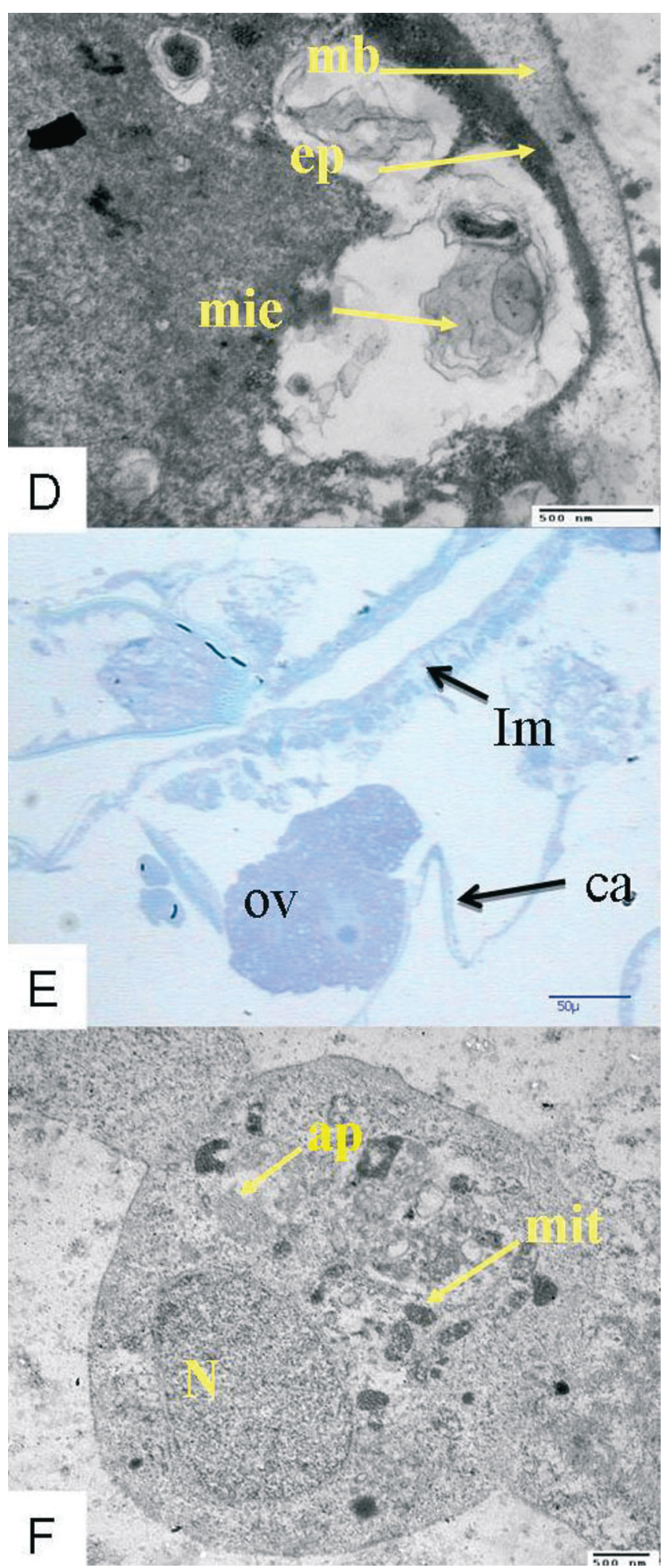

Fig. 2. Moina hutchinsoni. D. Estructuras mielínicas (mie) en el epitelio plano simple (ep) de la cámara incubatriz y membrana basal (mb). E. Ovocito (Ov) en el interior de la cámara incubatriz (ca), parte media del intestino (Im). F. Citoplasma (cit) de un ovocito (ov), con mitocondrias (mit), núcleo (N) y aparato de golgi (ag).

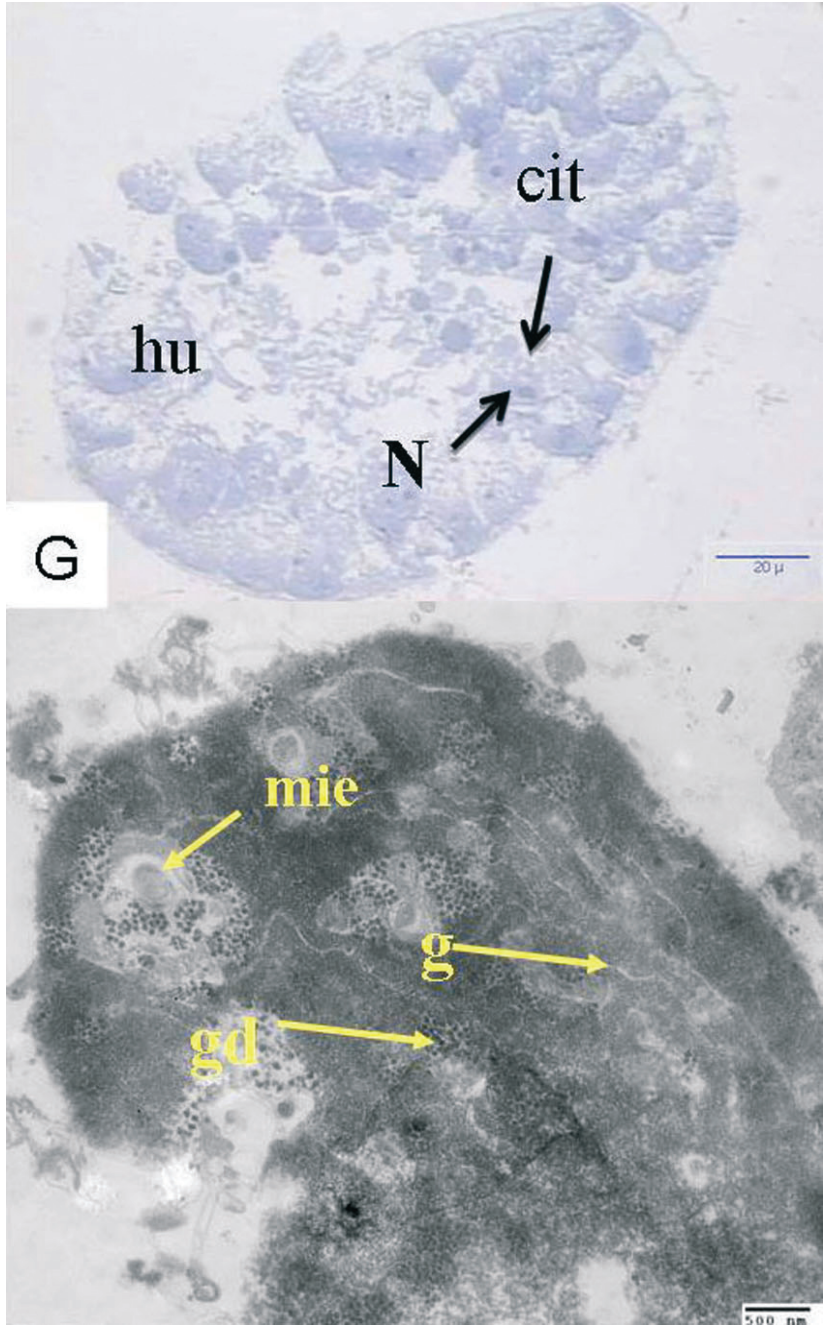

Fig. 3. Moina hutchinsoni. G. Huevo (hu), núcleo (N), citoplasma (cit). H. Huevo en división celular. Célula conteniendo material granular electrodenso (gd) y material granular menos electro denso (g), estructuras mielínicas (mie).

\section{DISCUSIÓN}

Las descripciones de la cámara incubatriz para cladóceros se refieren principalmente a su localización anatómica tal es el caso de Fox para Daphnia, situándola en la región posterior debajo del caparazón dorsal, Martínez-Jerónimo et al. (2004), mencionan las características anatómicas de la cámara de $M o i-$ na hutchinsoni en un estudio de microscopía de barrido, por lo que la descripción histológica de sus componentes se realiza por primera vez, señalando que es una estructura sencilla que protege los huevos y los embriones hasta su salida mediante la muda y en su caso al efipio.

La cámara incubatriz esta conformada por un epitelio plano simple y en la reproducción asexual contiene las etapas del desarrollo que son ovocito, huevo y embrión. 


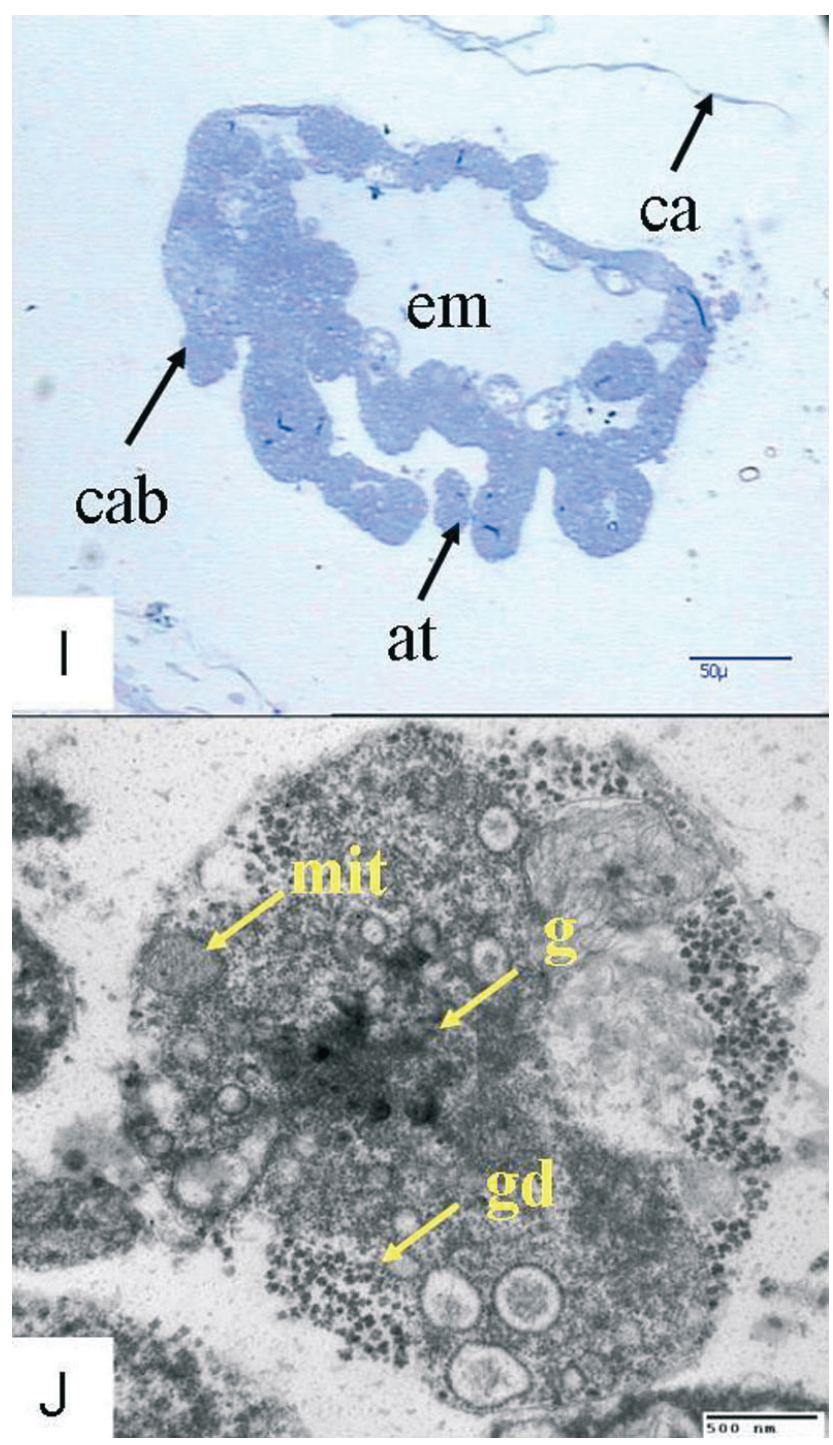

Fig. 4. Moina hutchinsoni. I. Cámara incubatriz (ca), embrión (em), cabeza del embrión (cab), apéndices toráxicos (at).J. Célula del cuerpo del embrión. Mitocondrias (mit), material granular electrón denso (gd) y material granular menos electrón denso $(\mathrm{g})$.

Existen trabajos histológicos de crustáceos como es el caso de Asellus aquaticus un isopodo donde estudian el ovario y los oviductos (Erkan, 1998), pero no existen trabajos histológicos en cladóceros por lo que esta es la primera contribución histológica en específico de Moina hutchinsoni.

Las estructuras o figuras mielínicas que se observan en el epitelio de la cámara incubatriz en los cortes finos, pueden ser las encargadas de la fijación del oxígeno o ser productos de la destrucción de las células epiteliales o bien proteger las etapas embrionarias en la reproducción asexual y en la sexual ser las formadoras de las capas que recubren al efipio. Esto se basa en los resultados obtenidos por Castejón (2008), quien realizó estudios en donde aparecen las estructuras mielinicas, Indicando que estas formaciones lamelares concéntricas provenientes de la membrana citoplásmica han sido relacionadas con la administración de drogas, exposición a hormonas, condiciones anóxico-isquémicas, gran variedad de procesos patológicos, procesos de envejecimiento, células tumorales, apoptósis, entre otras y con lisosomas secundarios rodeando organelos celulares degenerados. Moina, soporta bajas concentraciones de oxigeno, por lo que la presencia de las figuras mielinicas puede contribuir a que se reproduzca en altas cantidades en cuerpos de agua contaminados fuertemente que contienen bajas concentraciones de oxígeno.

El material electrodenso y menos electrodenso que se obtiene se debe a material almacenado cuya naturaleza deberá comprobarseposteriormente con estudios histoquímicos. También pudo ser causado por alteraciones en el laboratorio como lo indican Segnini De Bravo et al. (2005), quienes realizaron estudios en peces obteniendo la formación de dichas estructuras.

En este trabajo se presentan las etapas de ovocito, huevo y embrión, sin caracterizar todos los cambios del embrión, esto se debe a que los cambios de cada etapa embrionaria son muy rápidos y por lo tanto difíciles de secuenciar para un estudio de microscopía de transmisión, como lo mencionan Rottmann et al., para Moina. Es importante destacar que es necesario realizar un estudio para seguir las etapas del ciclo de vida de Moina hutchinsoni para determinar si la cámara incubatriz tiene sólo la función de protección o también la de secretar sustancias para la nutrición de los embriones o la formación del efipio, lo cual podría dar más luz acerca de esta estructura y sus relaciones con el desarrollo embrionario.

Este trabajo contribuye a la comprensión de los mecanismos involucrados en la reproducción de esta especie y su posible reintroducción en las áreas naturales en un lago salino contaminado por la fábrica de Sosa Texcoco. Actualmente se encuentra en condiciones de cultivo en el Laboratorio Hidrobiología Experimental de la Escuela Nacional de Ciencias Biológicas del IPN.

AGRADECIMIENTOS: Agradecemos a Laura Martínez Jerónimo del Laboratorio de Hidrobiología y a Jesús Rodríguez Estrada de la Escuela Nacional de Ciencias Biológicas por la facilitación de los ejemplares y apoyo en la realización del trabajo.

GÓNGORA-LANDEROS, E.; URÍA-GALICIA, E. A.; MARTÍNEZJERÓNIMO, F. F. \& LÓPEZ-VILLEGAS, E. O. Histological description of the brood-chamber of Moina hutchinsoni (Brem, 1937). Int. J. Morphol., 28(4):1025-1030, 2010.

SUMMARY: Cladocerans are parthenogenetic during the grea- 
ter part of the year. Populations consist entirely of females that reproduce asexually; in these females the ovary communicates through an oviduct with the brood chamber which is located at the rear inner shell border, near the heart and before the intestine. The eggs originating from the oviducts are deposited in the brood chamber and are incubated until the end of embryonic development. Moina is considered post embryonic development because juvenile or neonate organisms emerge fully formed and independent during moulting. In asexual reproduction the brood chamber contains the various stages of embryonic development denominated, oocyte, egg and embryo. At this stage the sexual gamogenetic contains an ephippium with two eggs. The brood chamber is formed histologically by a simple, plane epithelium that rests on a clear basal membrane continuous with the loose connective tissue, after which the shell can be located. Inside the brood chamber oocytes, eggs and some stages of embryonic development are identified, as well as fine semi optical and transmission microscopy cuts respectively.

KEY WORDS: Moina hutchinsoni; Ultrastructure; Broodchamber; Epifio; Embryonic development.

\section{REFERENCIAS BIBLIOGRÁFICAS}

Brusca, R. C. \& Brusca, G. J. Invertebrados. 2 ${ }^{\text {a. }}$ Ed. Madrid, Mc. Graw Hill, 2005. pp.76-9.

Banta, A. M. \& Brown, L. A. Control of sex in cladocera. III. Localization of the critical period for control of sex. Proc. Natl. Acad. Sci. USA, 15(2):72-80, 1929.

Castejón, O. J. Electron microscopy of myelin figures in normal and pathological tissues. Acta Microscopica, 17(2):13-9, 2008.

Curtis, H. \& Barnes, N. S. Biología. 6 ${ }^{a}$ Ed. Buenos Aires, Médica Panamaricana, 2001. p.1491.

De Bernardi, R. \& Peters, R. Why Daphnia? En: Peters, R. \& De Bernardi, R. Daphnia. Mem. Ist. Ital. Idrobiol., 45:1-9, 1987.

Elías, G. M.; Suárez, M. E.; Gutierrez, A. M. A.; Silva, B. M.; Granados, R. J. G. \& Garfías, E. T. Cladocera y copepoda de aguas continentales de México. Guía ilustrada. Iztacala, SEMARNAT, UNAM. 2008. pp.5-10.

Erkan, B. M. Ultrastructural study on the ovarian wall and the oviduct of the Asellus aquaticus (Crustacea: Isopoda). Tr. J. Zool., 22:351-62, 1998 .

Fernando, C.; Paggi, J. \& Rajapaksa, R. Daphnia in tropical lowlands. En: Peters, R. \& De Bernardi, R. (Eds.) Daphnia. Mem. Ist. Ital. Idrobiol, 45:107-41, 1987.

Forro, L. Mating behaviour in Moina brachiata (Jurine, 1820) (Crustacea, Anomopoda): Cladocera: the biology of model organisms. Hydrobiologia, 360(23):153-9, 1997.

Fox, R. Invertebrate anatomy online Daphnia magna Water flea, 2006. Disponible en: Http://Webs.Lander.Edu/Rsfox/Invertebrates/

Goulden, C. E. The systematic and evolution of the moinidae. Transactions of the america philosophical society, 58(1):101, 1968.
Kotov, A. A.; Elías-Gutiérrez, M. \& Granados-Ramírez, J. G. Moina dumonti Sp. Nov. (Cladocera, Anomopoda, Moinidae) from southern Mexico and Cuba, with comments on Moinid limbs. Crustaceana, 78(1):41-57, 2005.

Mac-Quhae, C. A.; Romero, C. \& Morales, D. A. Toxicidad aguda del hidróxido de sodio sobre Moina macrocopa (Crustácea, Branchiopoda). Ecotropicos, 20(1):24-30, 2007.

Martínez-Jerónimo, F.; Gutiérrez-Elías, M. \& Suárez-Morales, E. A redescription of Moina hutchinsoni, a rare cladoceran (Branchiopoda: Anomopoda) found in remnants of a mexican saline lake, with notes on its life history. J. Crust. Biol., 24(2):232-45, 2004.

Martínez-Jerónimo, F.; Rodríguez-Estrada, J. \& Martínez-Jerónimo, L. Daphnia exilis Herrick, 1895(Crustacea: Cladocera). Una especie zooplanctónica potencialmente utilizable como organismo de prueba en bioensayos de toxicidad aguda en ambientes tropicales y subtropicales. Rev. Int. Contam. Ambient., 24(4):153-9, 2008.

Martínez, R. J. P. Enciclopedia de la vida animal. Barcelona, Bruguera, 1976.

Montellano-Rosales, H. \& Mendoza-Vallejo, H. Manual de Laboratorio de Biología del Desarrollo. IPN, ENCB, 1994. pp.13-5.

Rodríguez-Estrada, J.; Villaseñor-Córdova, R. \& Martínez-Jerónimo, F. Efecto de la temperatura y tipo de alimento en el cultivo de Moina micrura (Kurz, 1874) (Anomopoda: Moinidae) en condiciones de laboratorio. Hidrobiológica, 13(3):239-46, 2003.

Rottmann, R. W.; Graves, S. J.; Watson, C. \& Yanong R. P. E. Culture techniques of Moina: the ideal Daphnia for feeding to freshwater fish fry. University of Florida. This document is circular 1054, one of a series from the department of fisheries and aquatic sciences, 2003.

Scharm, F. R. Crustacea. Oxford, Oxford University Press, 1986.

Segnini De Bravo, M. I.; Medina, J.; Marcano, S.; Boada-Sucre, A. \& Finol, H. Efectos del herbicida 2-cloro-2,6-bis-etilaminas-triazina, sobre algunos tejidos de Colossoma macropomum Cuvier, 1818 (Pisces: Characidae). Efectos de un herbicida en tejidos de C. Macropobol. Instituto Oceanográfico de Venezuela, Universidad de Oriente, 44(1):51-7, 2005.

Villalobos, M. J. \& González, E. J. Estudios sobre la biología y ecología de Ceriodaphnia cornuta Sars: una revisión. Interciencia, 31(5):351-7, 2006.

\section{Dirección para correspondencia: \\ Elizabeth Góngora-Landeros \\ Escuela Nacional de Ciencias Biológicas, IPN. \\ MÉXICO}

Email: eli_gongora_landeros@yahoo.com.mx

Recibido : 04-06-2010

Aceptado: 24-08-2010 